\title{
Erratum to: Output Control of the Longitudinal Motion Spectrum of a Single-Rotor Helicopter
}

\author{
N. E. Zubov ${ }^{a, *}$, V. N. Ryabchenko ${ }^{a}$, and I. V. Sorokin ${ }^{b}$ \\ ${ }^{a}$ Bauman Moscow State Technical University, ul. 2-ya Baumanskaya 5, Moscow, 105005 Russia \\ ${ }^{b}$ Korolev Rocket and Space Corporation Energiya, ul. Lenina 4a, Korolev, Moscow region, 141070 Russia \\ *e-mail:nezubov@bmstu.ru \\ Received November 9, 2020
}

DOI: $10.3103 /$ S1068799820030319

The TeX presentation of formulas was updated in HTML file.

The original article can be found online at https://doi.org/10.3103/S1068799820020099. 